\title{
Detection of herbicide residues in peppermint using QuEChERS techniqe
}

\author{
Oznaczanie pozostałości herbicydów w mięcie \\ z wykorzystaniem techniki QuEChERS
}

\author{
Magdalena Słowik-Borowiec, Ewa Szpyrka, Aneta Matyaszek, \\ Magdalena Podbielska, Anna Kurdziel, Julian Rupar
}

\begin{abstract}
Summary
The aim of this study was to evaluate the utility of the QuEChERS (quick, easy, cheap, effective, rugged and safe) sample preparation technique coupled with gas chromatography with electron capture and nitrogen phosphorus detection (GC-ECD/NPD gas chromatography with electron capture and nitrogen phosphorus detection) for the analysis of pesticide residues in peppermint. Validation experiments were carried out for 10 compounds belonging to the group of herbicides at two spiking levels from 0.01 to $0.524 \mathrm{mg} / \mathrm{kg}$. The obtained results were highly satisfactory and met the criteria recommended by the European Union document SANCO/12495/2011. The compounds showed recoveries in the range of 70-120\% and repeatability (relative standard deviation) equal to or less then $20 \%$, with the except for chloridazon and S-metolachlor. The method used, which was based on the QuEChERS allowed to obtain high quality pesticide residue results with a reduced number of analytical steps and a lower glassware and solvent consumption.
\end{abstract}

Key words: peppermint, gas chromatography, pesticide residues, QuEChERS

\section{Streszczenie}

Celem badań było sprawdzenie przydatności techniki ekstrakcji/oczyszczania zwanej QuEChERS (quick, easy, cheap, effective, rugged and safe) w połączeniu z chromatografią gazową z detekcją wychwytu elektronów i azotowo-fosforową (GC-ECD/NPD - gas chromatography with electron capture and nitrogen phosphorus detection) w badaniach pozostałości środków ochrony roślin w mięcie. Walidację przeprowadzono dla 10 związków należących do grupy herbicydów na 2 poziomach wzbogacenia od 0,01 do $0,524 \mathrm{mg} / \mathrm{kg}$. Uzyskane wyniki były zadowalające i spełniały wymagania zaleceń europejskich SANCO/12495/2011. Odzysk dla badanych związków mieścił się w przedziale 70-120\%, a powtarzalność wyrażona względnym odchyleniem standardowym była mniejsza lub równa 20\%, wyjątek stanowiły chloridazon i S-metolachlor. Zastosowana technika, oparta na QuEChERS pozwoliła uzyskać prawidłowe wyniki przy minimalnej liczbie etapów procesu analitycznego oraz niewielkim zużyciu odczynników i szkła laboratoryjnego.

Słowa kluczowe: mięta pieprzowa, chromatografia gazowa, pozostałości środków ochrony roślin, QuEChERS

Instytut Ochrony Roślin - Państwowy Instytut Badawczy

Terenowa Stacja Doświadczalna

Langiewicza 28, 35-101 Rzeszów

m.borowiec@iorpib.poznan.pl 


\section{Wstęp / Introduction}

Oznaczanie pozostałości środków ochrony roślin (ś.o.r.) jest ważne $\mathrm{z}$ punktu widzenia bezpieczeństwa zdrowotnego człowieka, dlatego niezbędna jest kontrola ich poziomów pozostałości w żywności z zastosowaniem właściwie dobranych metod analitycznych.

Chlorydazon, dimetenamid-P, flufenacet, lenacyl, metazachlor, metrybuzyna, napropamid, pendimetalina, S-metolachlor oraz terbutyloazyna są substancjami czynnymi (s.cz.) preparatów herbicydowych zarejestrowanych w Polsce. Wiele pozycji literaturowych podaje metody oznaczania tych substancji w wodzie lub glebie, jednak o wiele bardziej skomplikowana jest ich analiza w żywności pochodzenia roślinnego czy zwierzęcego. Pozostałości tych s.cz. oznaczane są głównie metodami wysokosprawnej chromatografii cieczowej z detekcją UV (HPLC-UV - high-performance liquid chromatography with ultrafiolet detection) lub w połączeniu ze spektrometrią mas (HPLC-MS/MS - high-performance liquid chromatography with tandem mas spectrometry), a także metodami chromatografii gazowej ze spektrometrią mas (GC-MS - gas chromatography with mas spectrometry) (Cessna 1998; Hirahara i wsp. 2005; EFSA 2007, 2008, 2009, 2012; Ferrer i wsp. 2005).

Celem badań było sprawdzenie przydatności techniki opartej na metodzie QuEChERS (Anastassiades i Lehotay 2003) w połączeniu $\mathrm{z}$ chromatografią gazową $\mathrm{z}$ detekcją wychwytu elektronów i azotowo-fosforową (GC-ECD/ NPD) w analizie wybranych s.cz. herbicydów w mięcie.

\section{Materiały i metody / Materials and methods}

Walidacji poddano 10 s.cz. ś.o.r. należących do grupy herbicydów. Były to: chlorydazon, dimetenamid-P, flufenacet, lenacyl, metazachlor, metrybuzyna, napropamid, pendimetalina, S-metolachlor oraz terbutyloazyna.

Materiałem wykorzystanym do badań była świeża mięta, w której po wstępnej analizie, nie stwierdzono obecności wyżej wymienionych s.cz.
Walidację przeprowadzono wzbogacając próbki mięty mieszaninami wzorców na 2 poziomach: od 0,010 do $0,524 \mathrm{mg} / \mathrm{kg}$. Dla każdego z poziomów wykonano 5 powtórzeń.

W badaniach wykorzystano zestawy soli i sorbentów SampliQ firmy Agilent Technologies (USA) oraz certyfikowane materiały odniesienia (Dr. Ehrenstorfer, Niemcy).

Próbki mięty $(5 \mathrm{~g}) \mathrm{z}$ dodatkiem wody $(10 \mathrm{ml})$ wzbogacone odpowiednimi mieszaninami certyfikowanych wzorców odniesienia, ekstrahowano acetonitrylem (10 ml) z udziałem soli, zawierającej: chlorek sodu, sekwiwodny wodorocytrynian disodu, cytrynian trisodu i bezwodny siarczan (VI) magnezu. Część ekstraktu acenitrylowego oczyszczano techniką dyspersyjnej ekstrakcji do fazy stałej (d-SPE - dispersive solid phase extraction) z wykorzystaniem soli i adsorbentów, tj. PSA (Primary Secondary Amine), węgiel aktywny i bezwodny siarczan magnezu. Oznaczenia pozostałości ś.o.r. w otrzymanych ekstraktach wykonano na chromatografie gazowym Agilent 6890 sterowanym za pomocą oprogramowania ChemStation (wersja Rev. A. 10.02), wyposażonego w kolumnę chromatograficzną DB-1701 $(30 \mathrm{~m} \times 0,25 \mathrm{~mm} \times 0,25 \mu \mathrm{m})$ podłączoną jednocześnie do detektora wychwytu elektronów (EC - electron capture detector) oraz detektora azotowo-fosforowego (NP - nitrogen phosphorus detector) za pomocą uniwersalnego Y-splittera. Zastosowano następujący program temperaturowy pieca kolumny: temperatura początkowa $100^{\circ} \mathrm{C} \rightarrow 20^{\circ} \mathrm{C} / \mathrm{min} \rightarrow 180^{\circ} \mathrm{C}-4 \mathrm{~min} \rightarrow$ $20^{\circ} \mathrm{C} / \mathrm{min} \rightarrow 220^{\circ} \mathrm{C}-5 \mathrm{~min} \rightarrow 20^{\circ} \mathrm{C} / \mathrm{min} \rightarrow 260^{\circ} \mathrm{C}$ - 48 min. Łączny czas analizy wynosił 65 minut. Ekstrakt dozowano na kolumnę $\mathrm{w}$ objętości $2 \mu \mathrm{l}$ za pomoca automatycznego podajnika próbek. Temperatura detektora EC wynosiła $270^{\circ} \mathrm{C}$, detektora NP $300^{\circ} \mathrm{C}$. Aparat pracował w trybie stałego ciśnienia. Jako gazu nośnego użyto azotu o czystości 6.0 (Słowik-Borowiec i wsp. 2012).

\section{Wyniki i dyskusja / Results and discussion}

Wykonane testy walidacyjne wykazały, że oznaczone związki uzyskały bardzo dobrą liniowość odpowiedzi

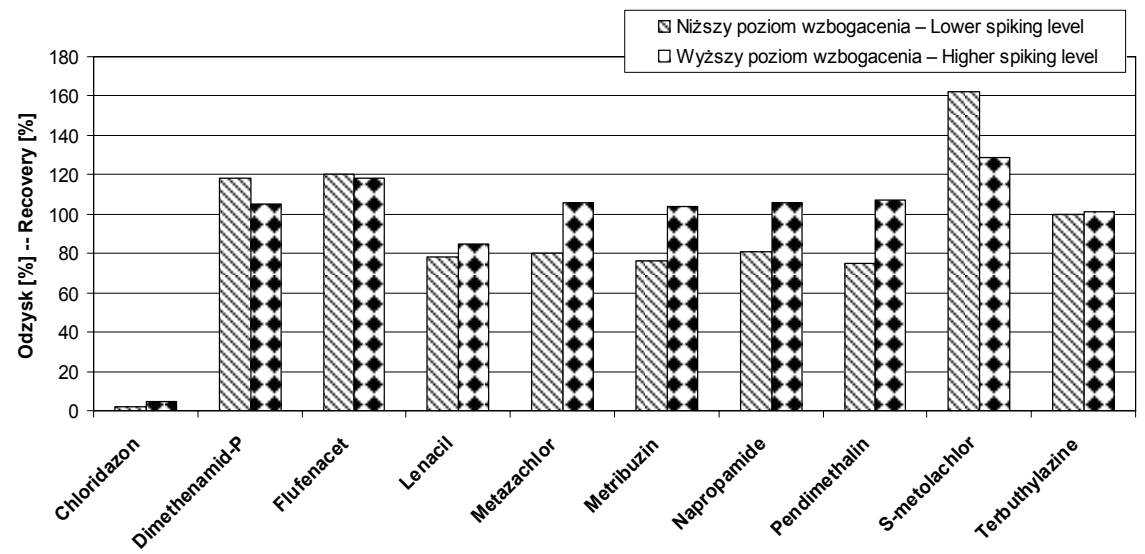

Rys. 1. Odzyski badanych substancji czynnych dla 2 poziomów wzbogacenia:

a) niższy poziom wzbogacenia - zakres stężeń dla poszczególnych substancji od 0,01 do $0,05 \mathrm{mg} / \mathrm{kg}$

b) wyższy poziom wzbogacenia - zakres stężeń dla poszczególnych substancji od 0,10 do $0,52 \mathrm{mg} / \mathrm{kg}$

Fig. 1. Recoveries of the analysed active substances at two spiking levels:

a) lower spiking level - concentration from 0.01 to $0.05 \mathrm{mg} / \mathrm{kg}$

b) higher spiking level - concentration from 0.10 to $0.52 \mathrm{mg} / \mathrm{kg}$ 
detektora $\left(\mathrm{R}^{2} \geq 0,99\right)$ w zakresie stężeń $0,01-0,524 \mathrm{mg} / \mathrm{kg}$. Wyjątek stanowił S-metolachlor, którego współczynnik determinacji $\mathrm{R}^{2}$ wyniósł $0,23 \mathrm{w}$ zakresie stężeń 0,012 $0,122 \mathrm{mg} / \mathrm{kg}$. Przyczyną braku liniowości mogło być wystąpienie zanieczyszczenia, które uniemożliwiło poprawne oznaczenie tej substancji.

Odzyski dla dimetenamidu-P, flufenacetu, lenacylu, metazachloru, metrybuzyny, napropamidu, pendimetaliny oraz terbutyloazyny mieściły się w granicach 70-120\% przy względnym odchyleniu standardowym (RSD) $\leq 20 \%$ i spełniały wymagania zaleceń europejskich (SANCO 2011) (rys. 1). Średni odzysk dla chlorydazonu wyniósł mniej niż 10\% [związek charakteryzował się dobrą liniowością, współczynnik determinacji $\left(\mathrm{R}^{2}\right)$ dla wyznaczonej krzywej kalibracji wynosił 1,000]. Dla tego związku przeprowadzono dodatkową fortyfikację próbek $\mathrm{z}$ zastosowaniem $\mathrm{w}$ etapie oczyszczania jedynie bezwodnego siarczanu magnezu i PSA. Eksperyment dowiódł, że w próbkach oczyszczanych na kolumnach bez węgla aktywnego odzysk dla chlorydazonu wzrósł i wyniósł $60 \%$ i był o wiele wyższy od odzysków próbek oczyszczanych z udziałem węgla aktywnego.

Granice oznaczalności dla s.cz. herbicydów wynosiły odpowiednio: dla metazachloru $-0,01 \mathrm{mg} / \mathrm{kg}$, dla flufenacetu, metrybuzyny, napropamidu, pendimetaliny oraz terbutyloazyny - 0,02 mg/kg, natomiast dla lenacylu i dimetenamidu-P $-0,05 \mathrm{mg} / \mathrm{kg}$. Granice te są niższe od najwyższych dopuszczalnych poziomów (NDP) określonych w Rozporządzeniu Unijnym (2005) dla mięty (wyjątek stanowi dimetenamid-P), dlatego też metoda może zostać wykorzystana do badań komercyjnych próbek mięty.

$\mathrm{W}$ odniesieniu do metod podanych w literaturze dla matryc roślinnych granice oznaczalności wynoszą dla: metazachloru 0,01-0,05 mg/kg (EFSA 2008), flufenacetu $0,02 \mathrm{mg} / \mathrm{kg}$ (EFSA 2012), metrybuzyny $0,02-0,05 \mathrm{mg} / \mathrm{kg}$ (Cessna 1998), pendimetaliny, napropamidu i dimetenamidu odpowiednio: 0,05; 0,05; 0,01 $\mathrm{mg} / \mathrm{kg}$ (Hirahara i wsp. 2005), dla terbutyloazyny $0,01 \mathrm{mg} / \mathrm{kg}$ (Ferrer i wsp. 2005), natomiast dla lenacylu $0,02 \mathrm{mg} / \mathrm{kg}$ (EFSA 2009). Dla opracowanej metody tylko trzy związki mają granice wyższe od przedstawionych w literaturze.
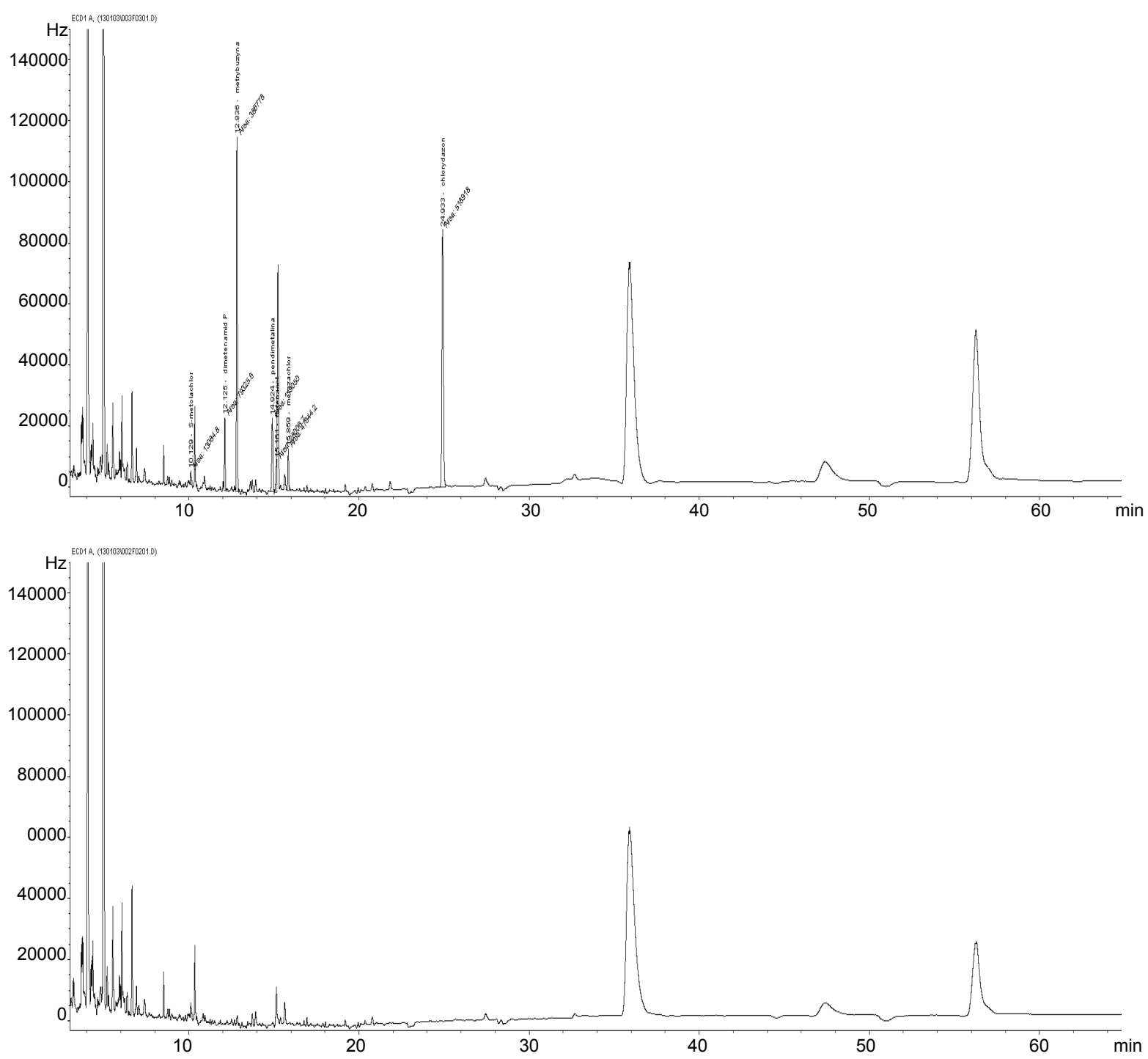

Rys. 2. Chromatogram próbki mięty wzbogaconej mieszaniną herbicydów oraz próbki mięty bez pozostałości ś.o.r. dla detektora EC Fig. 2. Chromatogram of peppermint sample fortified with herbicide mixture and sample without pesticide residues for EC detector 

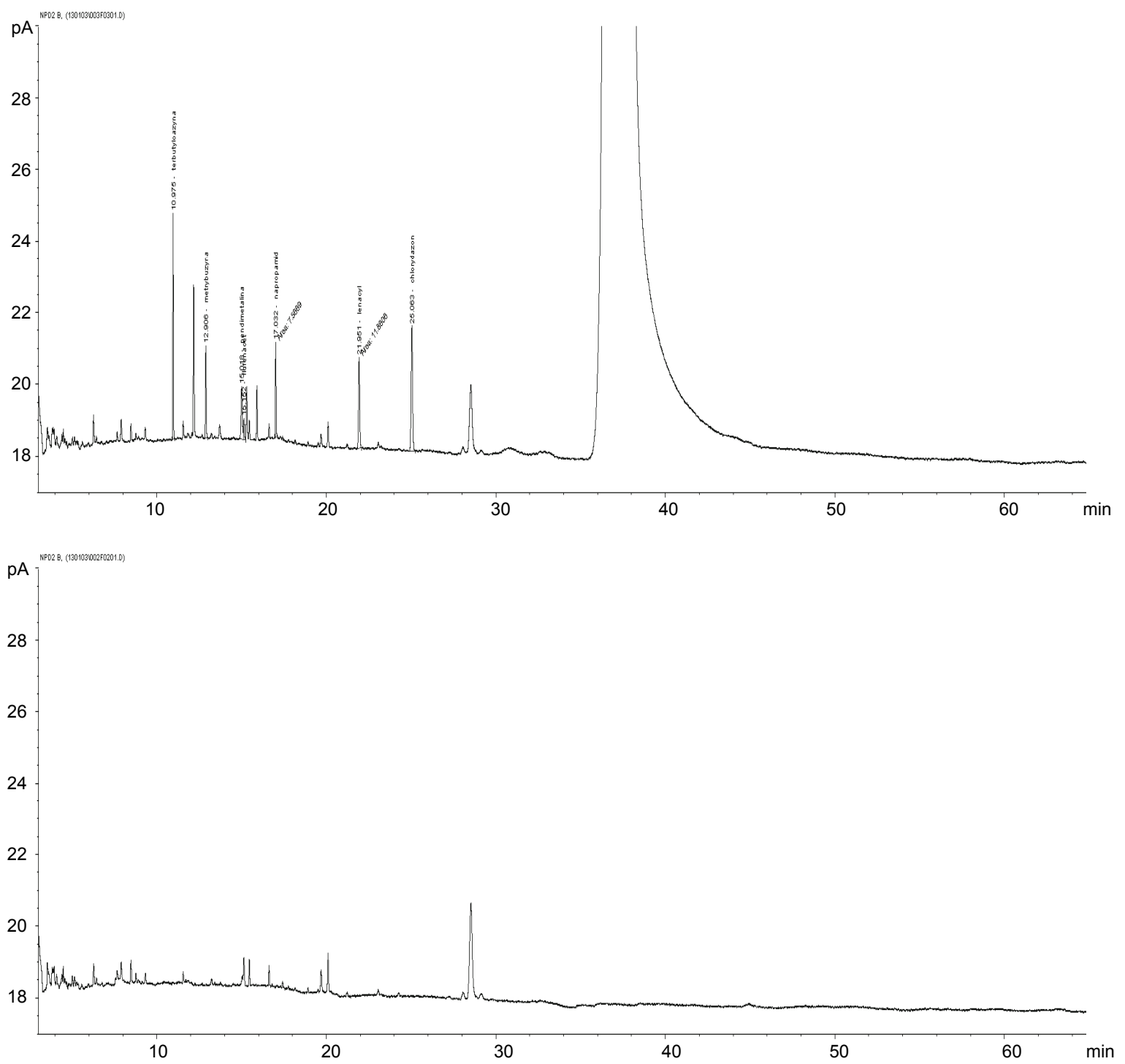

Rys. 3. Chromatogram próbki mięty wzbogaconej mieszaniną herbicydów oraz próbki mięty bez pozostałości ś.o.r. dla detektora NP

Fig. 3. Chromatogram of peppermint sample fortified with herbicide mixture and sample without pesticide residues for NP detector

Zastosowana technika przygotowania ekstraktów opierająca się na metodzie QuEChERS pozwala w sposób zadowalający oczyścić matrycę próbki z interferentów, które utrudniają analizę chromatograficzną. Chromatogramy próbki mięty nie zawierającej pozostałości ś.o.r. oraz próbki wzbogaconej mieszaniną herbicydów dla detektora EC i NP przedstawiają rysunki 2. i 3.

Dane uzyskane w eksperymentach walidacyjnych dla wybranych herbicydów, jak i z wcześniej przeprowadzonych walidacji (Słowik-Borowiec i wsp. 2012) potwierdzają przydatność zastosowania techniki QuEChERS w analizie pozostałości ś.o.r. Jednak zastosowanie zestawów do oczyszczania zawierających węgiel aktywny (zestawy te przeznaczone są do próbek roślinnych z dużą zawartością barwników, głównie chlorofilu), niesie ze sobą ryzyko strat substancji, które mogą adsorbować się na nim.

Zastosowanie techniki oczyszczania i ekstrakcji QuEChERS w porównaniu $\mathrm{z}$ dotychczas stosowaną techniką (Szpyrka i wsp. 2004; Sadło i wsp. 2006) pozwala na znaczne zmniejszenie ilości zużywanych odczynników chemicznych oraz krótszy czas przygotowania ekstraktów w laboratorium. Dzięki lepszemu oczyszczeniu ekstraktu możliwa jest analiza próbki na detektorze EC, co znacznie zwiększa zakres analityczny.

\section{Wnioski / Conclusions}

Uzyskane wyniki, dla przeprowadzonego procesu walidacji, spełniają wymagania zaleceń europejskich SANCO/12495/2011 dla wszystkich badanych herbicydów z wyjątkiem chlorydazonu i S-metolachloru. Opracowana metoda może mieć zastosowanie w rutynowych badaniach pozostałości ś.o.r. Jest to metoda szybka, prosta, efektywna i tania, która w znacznym stopniu pozwala na pozbycie się uciążliwych substancji z matrycy. 


\section{Literatura / References}

Anastassiades M., Lehotay S. 2003. Fast and easy multiresidue method employing acetonitrile extraction/partitioning and „dispersive SPE" for the determination of pesticide residues in produce. J. AOAC Int. 86: 412-431.

Cessna A.J. 1998. Metribuzin residues in lentil following postemergence application. Can. J. Plant Sci. 78: 167-169.

EFSA Scientific Report. 2007. Conclusion on the peer review of chloridazon 108, 82 pp. DOI: 10.2903/j.efsa.2007.

EFSA Scientific Report. 2008. Conclusion on the peer review of metazachlor 145, 132 pp. DOI: 10.2903/j.efsa.2008.

EFSA 2009. Conclusion on the peer review of the pesticide risk assessment of the active substance lenacil. J. EFSA 7 (10), p. 1326.

EFSA Reasoned opinion. 2012. Reasoned opinion on the review of the existing maximum residue levels (MRLs) for flufenacet according to Article 12 of Regulation (EC) No 396/2005. J. EFSA 10 (4), p. 2689.

Ferrer C., Gómez M.J., Garcia-Reyes J.F., Ferrer I., Thurman E.M., Fernández-Alba A.R. 2005. Determination of pesticide residues in olives and olive oil by matrix soild-phase dispersion followed by gas chromatography/mass spectrometry and liquid chromatography/tandem mass spectrometry. J. Chromatogr A 1069 (2): 183-194.

Hirahara Y., Kimura M., Inoue T., Uchikawa S., Otani S., Haganuma A., Matsumoto N., Hirata A., Maruyama S., Iizuka T., Ukyo M., Ota M., Hirose H., Suzuki S., Uchida Y. 2005. Validation of multiresidue screening methods for the determination of 186 pesticides in 11 agricural products using gas chromatography (GC). J. Health Sci. 51 (5): 617-627.

Rozporządzenie (WE) nr 396/2005 Parlamentu Europejskiego i Rady z dnia 23 lutego 2005 r. zmieniające dyrektywę Rady 91/414/EWG w sprawie najwyższych dopuszczalnych poziomów pozostałości pestycydów w żywności i paszy pochodzenia roślinnego i zwierzęcego oraz na ich powierzchni (Dz. Urz. UE, L 70/1, z dnia 16.03.2008 r., z późn. zm.).

Sadło S., Szpyrka E., Rogozińska K., Rupar J. 2006. Występowanie pozostałości niektórych pestycydów w mięcie pieprzowej Mentha piperita L. w latach 2003-2005. Rocz. PZH 57: 211-216.

SANCO/12495/2011. 2011. Method validation and quality control procedures for pesticide residues analysis in food and feed, $40 \mathrm{pp}$.

Słowik-Borowiec M., Szpyrka E., Walorczyk S. 2012. Analysis of pesticide residues in fresh peppermint, Mentha piperita L., using the quick easy cheap effective rugged and safe method (QuEChERS) followed by gas chromatography with electron capture and nitrogen phosphorus detection. Bull. Environ. Contam. Toxicol. 89 (3): 633-637.

Szpyrka E., Rogozińska K., Rupar J., Sadło S. 2004. Metody oznaczania i występowanie pozostałości składników aktywnych niektórych środków ochrony roślin w mięcie pieprzowej (Mentha piperita L.). [Determination of active ingredient residues of some plant protection products in peppermint (Mentha piperita)]. Prog. Plant Prot./Post. Ochr. Roślin 44 (2): 1142-1144. 